\title{
Quantitative Risk Assessment of Maritime Accident for Different Types in Korea
}

\author{
Yoo-Kyung Won11), Dong-Jin Kim²)
}

\begin{abstract}
Most of the international trade in Korea is made by sea transportation using ships, and maritime accidents are not only harmful to people but also lead to negative ripple effects in terms of national competitiveness. However, there are not many theoretical studies on the risk of maritime accidents in Korea, and in particular, there is no criteria for assessing the risk of marine accidents. Therefore, in this study, we propose risk matrix using frequency and fatality to evaluate the risk by nine accident types using the ship accident data of the past 10 years. As a result of the analysis, it was found that the collision was the most dangerous both in frequency and fatality, and capsizing, sinking, death-injury were found to be relatively low in frequency but high in fatality. Fire explosion, stranding, and touching were found to be relatively low compared to other types of accidents, while engine failure and miscellaneous types were low in fatality but high in frequency. Risk assessment based on these evaluation criteria will help decision makers establish and implement effective and practical accident mitigation measures for each type of accident.
\end{abstract}

Keywords : Risk Analysis, Risk Criteria, Risk Matrix, Risk Mitigation Measures, Ship Accident

\section{Introduction}

99\% of Korea's foreign trade cargoes are made by sea transportation through port, and maritime accidents are less frequent than other industrial accidents. However, when an accident occurs, it does not only result in human and physical damage, but also often lead to negative consequences towards weakening national competitiveness. In 2016, there were 3,121 maritime accidents in Korea. Of these, 2,097 fishing vessels accounted for about 67\% of all accidents and 596 non-fishing vessels were about $19 \%$ of them. This is an increase of $4 \%$ from 2,998 cases in 2015, and maritime accidents keep occurring every year. The number of death also increased

Received(June 30, 2018), Review Result(1st: July 13, 2018, 2nd: August 10, 2018), Accepted(September 10, 2018)

1) (Student) 46241 Dept. International Trade, Pusan National Univ., Jangjeon-dong, Geumjung-gu, Busan, Korea email: charmhanai@gmail.com

2) (Professor, Corresponding Author) 46241 Dept. International Trade, Pusan National Univ., Jangjeondong, Geumjung-gu, Busan, Korea

email: ssskdj@hanmail.net 
from 395 in 2015 to 411 in 2016. The government establishes various accident mitigation measures to reduce the number of maritime accidents and fatality. However, in order for the measures to be effective, a risk analysis of accidents must be performed first based on which, appropriate measures for the type of accident should be established.

Currently, there are not many studies on the risk assessment of maritime accidents in Korea. In particular, there is no risk criteria to evaluate the risk. Therefore, in this study, we calculate risk level of 9 different types of accidents and evaluate the risk using the maritime accident data for the past 10 years. In this context, we compare the risk level of each accident against the risk matrix consisting of two factors for accident risk estimation, frequency and fatality. The result will be helpful for the decision makers to establish appropriate accident mitigation measures in the future.

The remainder of the study is following. Section 2 summarizes previous studies on the risk analysis of maritime accidents, and section 3 analyzes and evaluates the risk by accident type using the data from the Korea Maritime Safety Tribunal(KMST). Section 4 discusses limitations and future directions of research.

\section{Literature Review}

Ronza et al.[1] estimated the frequency of port accidents in the 1900s and calculated the risk using event tree diagram. Kim et al.[2] assessed the risk of fishing vessel accidents and selected the major factors to reduce occurrence of collision. The Ministry of Oceans and Fisheries[3] in the Maritime Safety Implementation Plan set up measures to reduce maritime accidents and fatality by $30 \%$ each. Chlomoudis et al.[4] conducted a risk analysis of terminal accidents in Greek ports and performed cost-benefit analysis to choose the most effective risk mitigation measures. Kim and Kwak[5] conducted a risk analysis on container vessel accidents and presented corresponding risk level using the FN curve criterion, and descrobed some mitigation measures to reduce the number of fatality. Kim and Kim[6] suggested a methodology for ship accidents in domestic ports and presented the resulting risk with FN curves. Akyildiz[7] described the procedure to apply the formal safety assessment(FSA) proposed by IMO to fishing vessel for risk calculation and introduced a risk matrix where each hazard was situated into a frequency and consequence category to evaluate the risk. Yip[8] investigated the port traffic risk in Hong Kong waters using the marine accidents data for 2001-2005 and showed that collisions are the most frequent accident when port traffic is heavy. 


\section{Vessel Accident Risk Analysis and Risk Assessment Using Risk Matrix}

\subsection{Risk Analysis by Accident Type}

The risk of an accident is expressed by a combination of the probability of occurrence (frequency) and the number of fatality(consequence) of an accident, and is generally expressed as a function of the frequency and consequence in the formula below.

$$
P \times C
$$

where $\mathrm{R}=$ risk of an accident, $\mathrm{P}=$ frequency of the accident (probability), and $\mathrm{C}=$ consequence of an accident (loss of life, environmental damage, economic damage, etc.). Frequency is defined as the ratio of the number of accidents of each type to the total number of accidents of all types and consequence is the fatality including injured and missing people from vessel accidents. The injured and missing people were converted to the number of fatality by conversion coefficient from the Kim (2013); death(1.00), injury(0.043), missing(0.996). In this study, we used past 10 years of accident data from the Korea Maritime Safety Tribunal(KMST) and classified accident type into 9 types (collision, touching, stranding, capsizing, fire - explosion, sinking, engine failure, death - injury, and etc.). With the formula (1), the risk level of each accident type is calculated and the risk level by accident type is shown in [Fig. 1] - [Fig. 3] below. In order to calculate the risk level of maritime accidents, the types of vessels were classified and analyzed for fishing vessel and non-fishing vessel, respectively and the overall vessel risk level was calculated considering both vessel types.

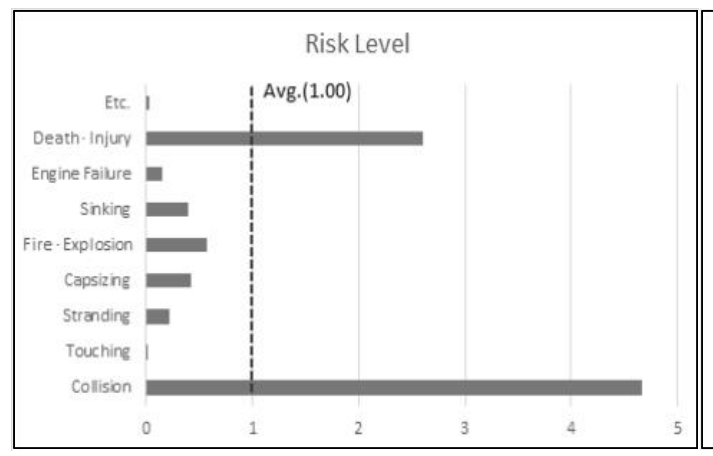

[Fig. 1] Risk of Fishing Vessel

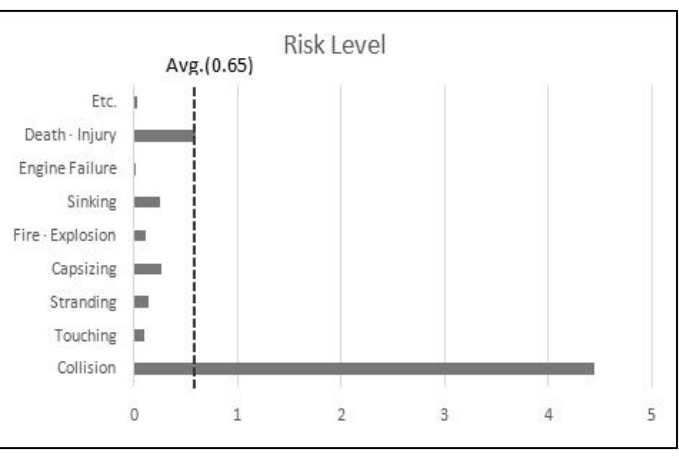

[Fig. 2] Risk of Non-fishing Vessel 


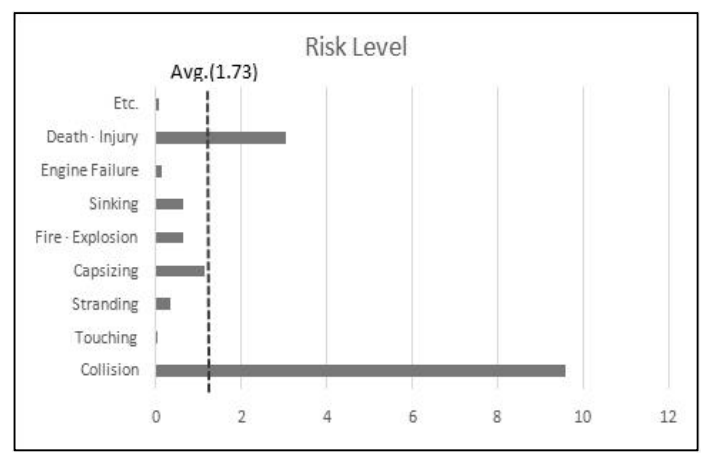

[Fig. 3] Overall Risk of All Vessel

As shown in [Fig. 1], the collision and the death - injury were higher than the average risk level of 1.00, and the risk level was higher in the order of fire · explosion, sinking and capsizing. Also, in the risk level of the non-fishing vessel accident, the collision was higher than the average risk level of 0.65 , followed by death · injury, sinking, and capsizing.

On the other hand, in the case of overall risk of all vessel in [Fig. 3], the collision and death - injury were higher than the average risk of 1.73 , and the risk was higher in the order of capsizing, sinking and fire - explosion. However, risk level above([Fig. 1] - [Fig. 3]) reveals only the risk ranking by accident type, and it is difficult to identify the frequency and the consequence of accidents.

\subsection{Risk Level by Accident Type}

[Fig. 4] - [Fig. 6] show the risk level by vessel type for a 10-year collision data from 2007 to 2016. The risk level for other types of accidents are summarized in Appendix. The $X$-axis represents the risk level and the Y-axis represents the year. The risk of accidents is randomly going up and down each year, and the risk of accidents for the last 5 years is relatively low compared to 2011 and earlier. The average risk level is high in the order of all vessel(9.60), fishing vessel(4.66) and non-fishing vessel(4.44). Specifically, fishing vessels have more than twice the average risk level in 2008 and 2010, and non-fishing vessels are almost three times the average in 2007 and 2009. In the case of all vessels, the risk level exceeded the average from 2007 to 2011, but it decreases in recent years. 


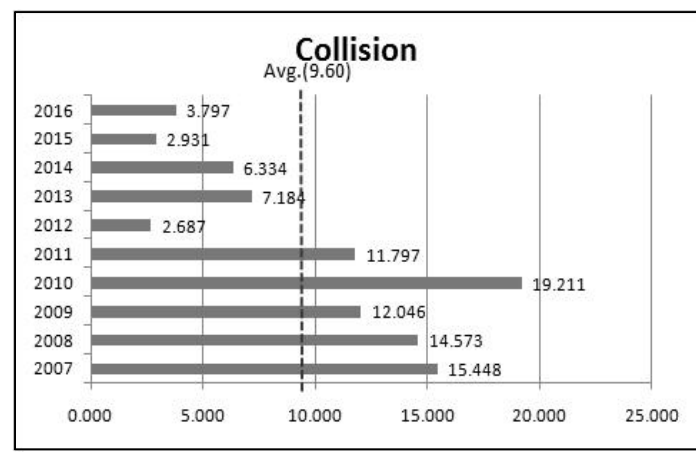

[Fig. 4] All Vessel

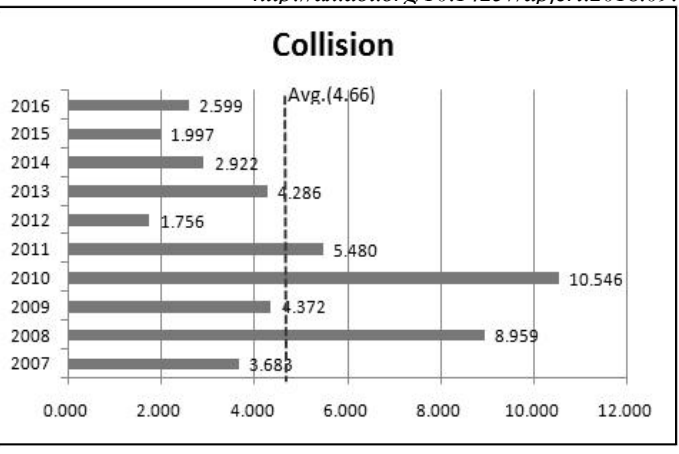

[Fig. 5] Fishing Vessel

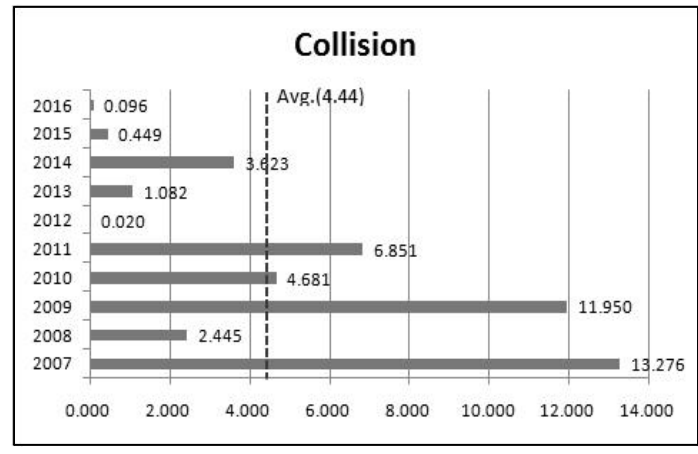

[Fig. 6] Non-fishing Vessel

\subsection{Risk Assessment by Risk Matrix}

In this section, we assess the risk by type (see [Fig. 7] - [Fig. 9]) against the risk matrix that can easily identify the types of risks. We use the frequency and the consequence of an accident to establish the risk matrix. As shown in the figures below, the $X$-axis shows the frequency of an accident $(\mathrm{P})$ and the $\mathrm{Y}$-axis shows the consequence of an accident $(\mathrm{C})$. The bold horizontal line represents the average of the $\mathrm{C}$, and the bold vertical line represents the average of the $\mathrm{P}$ of accident types. Based on these two lines, the risk matrix is divided into four regions. The first quadrant in the upper right-hand side is the area where the risk of accidents is high, i.e, the frequency and the number of fatality of a given accident is higher than the average. The second quadrant of the upper left shows the area where the frequency is low, but the number of fatality is high. In the third quadrant of the lower left side, the frequency and the number of fatality of an accident are low, so it is a relatively low risk area. Finally, in the fourth quadrant of the lower right, the frequency is high, but the number of fatality is relatively low. 
For example, in the risk matrix of a fishing vessel accident, the frequency and consequence of each type of accident are plotted as in [Fig. 7]. It is possible to make a relative comparison of the risks by accident type.

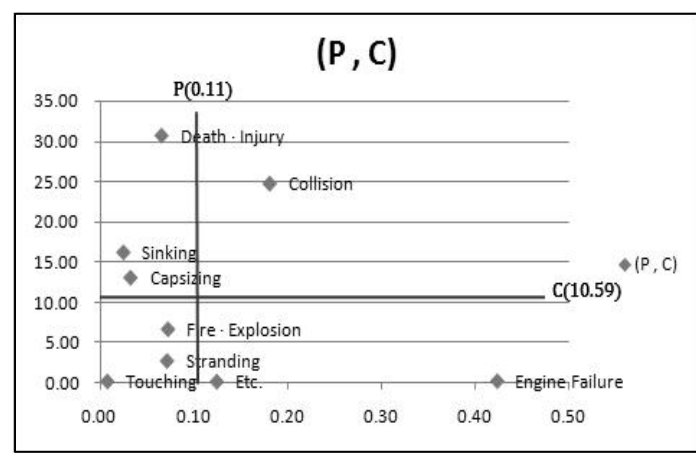

[Fig. 7] Risk Matrix of Fishing Vessel

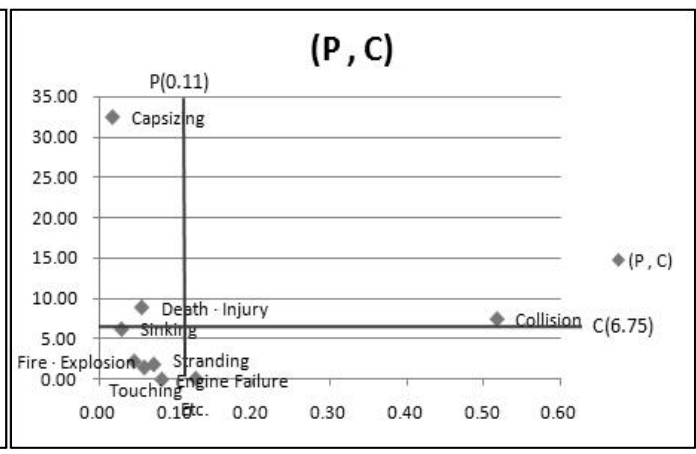

[Fig. 8] Risk Matrix of Non-fishing Vessel

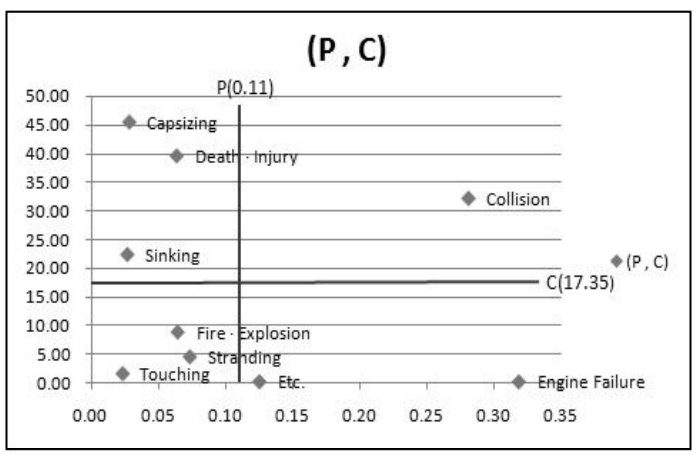

[Fig. 9] Risk Matrix of All Vessel

Collision is in the first quadrant showing the highest risk in all types of vessels, such as fishing vessel, non-fishing vessel, and all vessel. In the case of non-fishing vessel, the frequency of collision is relatively higher than the other vessel type (fishing vessel, all vessel), but the number of fatality is low. This indicates that a collision belongs to the highest risk area in all three type of vessel accidents, but the cause of an accident may be different from type to type.

In the second quadrant, it can be seen that death - injury and capsizing are included in all three type of vessel accident. First, in the case of death - injury, the number of fatality is higher than the average value in fishing vessel and all vessel, whereas the number of fatality in non-fishing vessel is not much different from the average. In the case of capsizing, as the number of fatality is higher than the average for non-fishing vessel and all vessel, the risk level is high. In the case of fishing vessel, the number of fatality of an accident is slightly 
above the average value.

In the third quadrant, which is the lowest risk area of the four quadrants, fire explosion, touching, and stranding are in all three types of vessel accidents. Finally, in the fourth quadrant, accidents caused by engine failure and miscellaneous types are common. In the case of fishing vessel and all vessel accidents, the frequency engine failure is higher than the average value, which increases the risk. On the other hand, the frequency is close to the average value for the non-fishing vessel.

\section{Conclusion}

In the international trade, the importance of sea transportation is growing, and the volume of goods transported by ship continues to increase. However, since maritime accidents have a negative effect on human and material damage as well as the national economy, many countries make great efforts to reduce maritime accidents. Korea has also prepared various measures to reduce maritime accidents by $30 \%$ in 2017. However, in order to apply these mitigation measures, an accurate risk analysis should be carried out first, and appropriate mitigation measures should be established for different types of accident. Since there is no risk assessment criteria in Korea, in this study, the risk of each accident type is calculated based on the accident data of the past 10 years and it is indicated in the risk matrix. Therefore, using the results of this study, it is possible to easily analyze the characteristics of frequency, and consequence of an accident for each type of accident and vessel, and to establish proper accident reduction measures according to various causes of accident.

The risk matrix used in this study is calculated based on 10 years of ship accident data. However, more accurate risk criteria should be set for future studies. Also, research needs to be improved to reduce the uncertainty inherited in risk calculation.

\section{References}

[1] A. Ronza, S. Félez, R. M. Darbra, S. Carol, J. A. Vílchez and J. Casal, Predicting the Frequency of Accidents in Port Areas by Developing Event Trees from Historical Analysis, Journal of Loss Prevention in the Process Industries, (2003), Vol.16, Issue 6, pp.551-560.

[2] W. S. Kim, J. H. Lee, S. J. Kim, H. S. Kim and Y. W. Lee, A Basic Study on Control Factor for the Marine Casualties of Fishing Vessel in Korea, Journal of Korea Society for Fishery Technology, (2013), Vol.49, No.1, pp.40-50. 
[3] Ministry of Oceans and Fisheries, Master Implement Plan for Maritime safety: Ministry of Oceans and Fisheries, (2017)

[4] C. I. Chlomoudis, P. L. Pallis and E. S. Tzannatos, Port Risk Assessment Methodology For Human Accidents in Container Terminals : Evidence from the Port of piraeus-GREECE, International Journal for Traffic and Transport Engineering, (2016), Vol.6, No.4, pp.368-377.

[5] D. J. Kim and S. Y. Kwak, Risk Analysis of Container Ship Accidents and Risk Mitigation Measures, Journal of Korean Society and Marine Environment \& Safety, (2016), Vol.22, No.3, pp.259-267.

[6] D. J. Kim and S. Y. Kim, A Methodology for Risk Analysis on Ship Accidents at Port Area, The Journal of Shipping and Logistics, (2008), Vol.59, pp.105-121.

[7] H. Akyildiz, Formal Safety Assessment of a Fishing Vessel, Gidb, (2015), pp.31-46.

[8] Yip, T. L., Port Traffic Risks - A Case Study of Accidents in Hong Kong Waters, Transportation Research, (2008), PartE 44, pp.921-931. 
Appendix 1. Risk Level by Accident Type of All Vessel
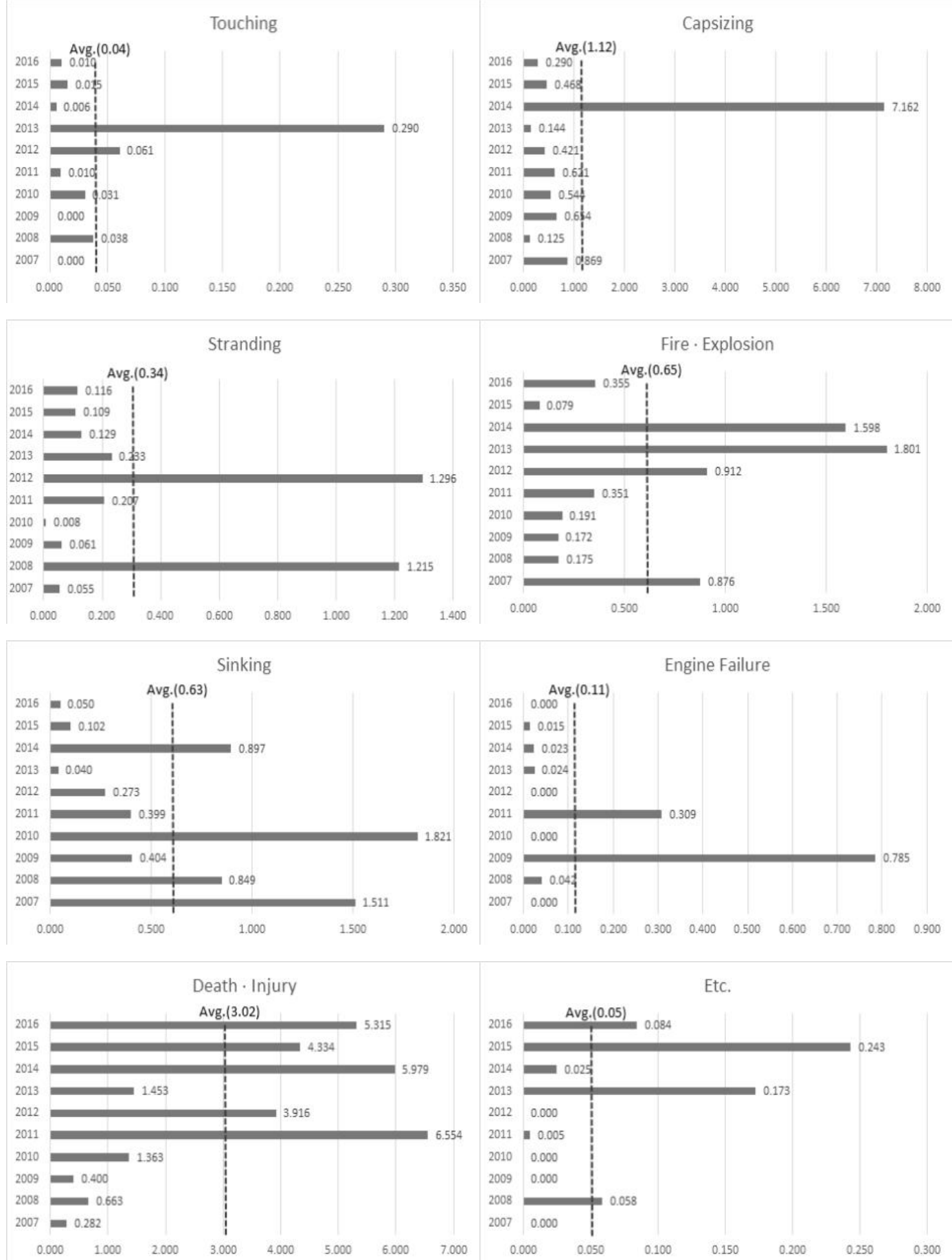


\section{Appendix 2. Risk Level by Accident Type of Fishing Vessel}
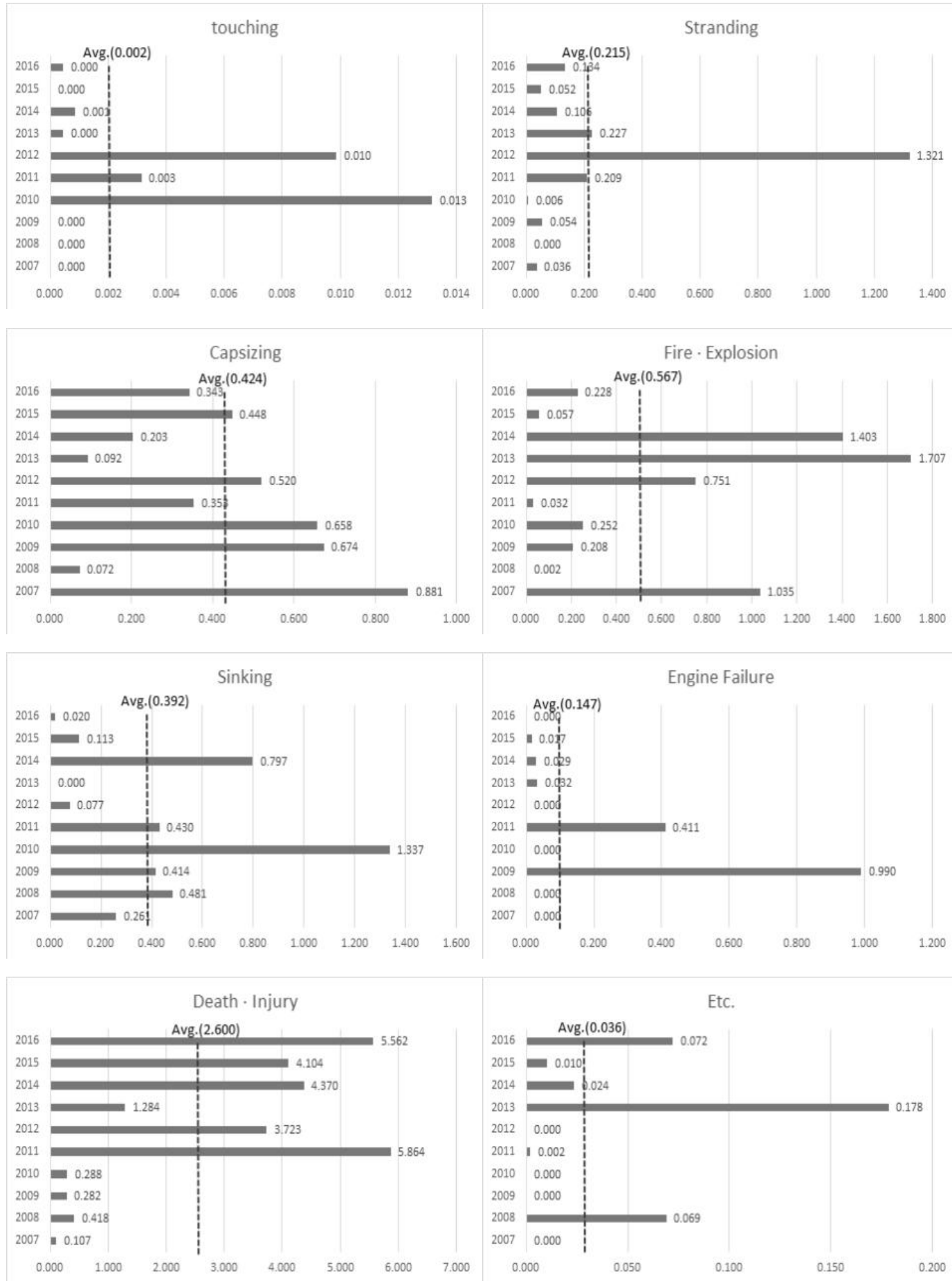


\section{Appendix 3. Risk Level by Accident Type of Non-fishing Vessel}
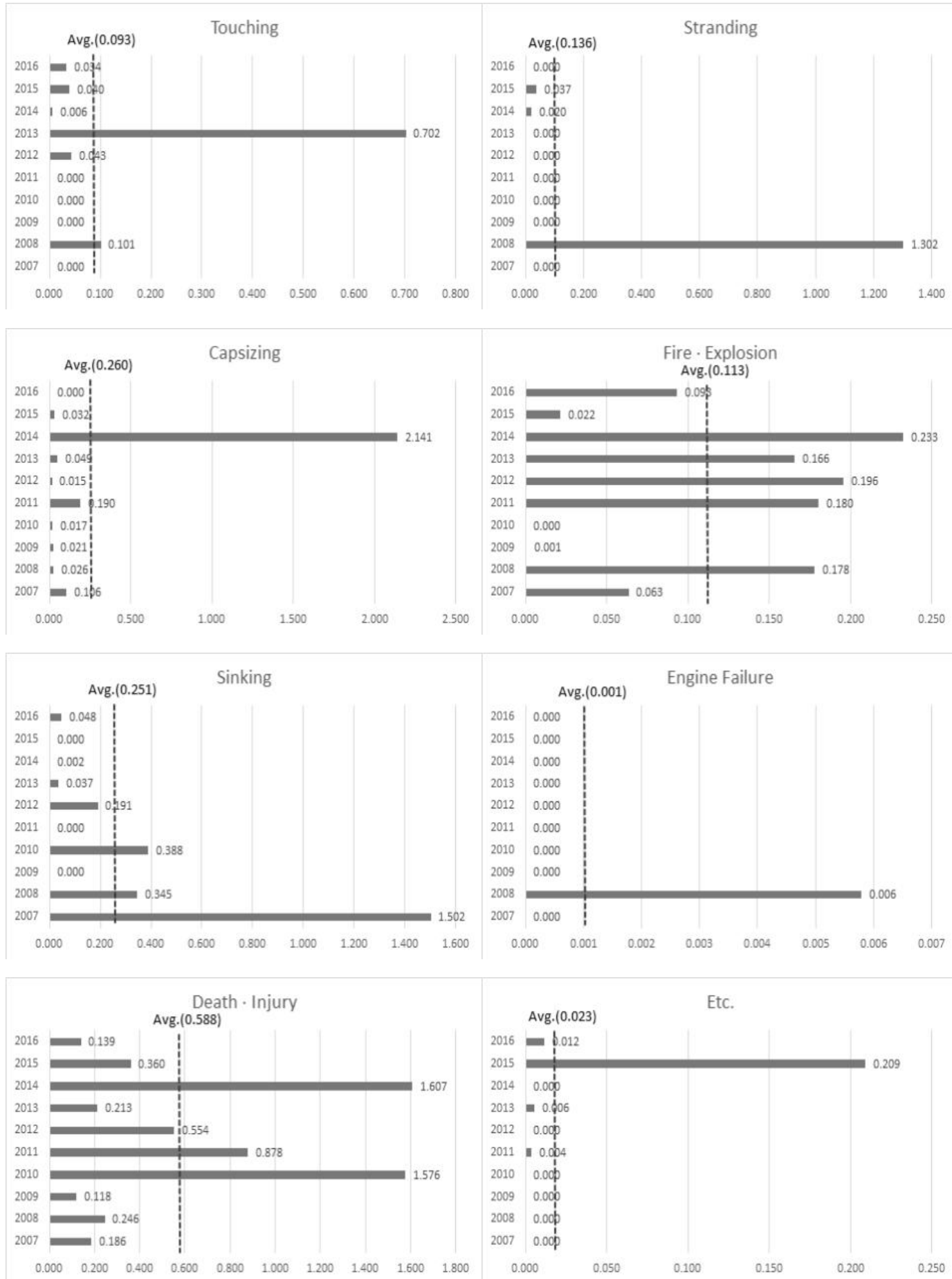